\title{
Deep brain stimulation for dystonia in Finland during 2007-2016
}

Rebekka M. Ortiz ${ }^{1,2^{*}}$ (D) Filip Scheperjans ${ }^{1,2}$ and Eero Pekkonen ${ }^{1,2}$

\begin{abstract}
Background: Dystonia is a movement disorder substantially affecting the quality of life and the ability to work. A proportion of patients does not respond to first line pharmacotherapy. Deep brain stimulation (DBS) is established as a primary operative treatment option for severe drug resistant dystonia. We studied dystonia patients treated with DBS in Finland between the years 2007-2016 to evaluate the use and outcomes of DBS treatment.

Methods: We analysed the hospital records of dystonia patients, who underwent DBS operation during 2007-2016 in Finland. The clinical and technical parameters were recorded as well as preoperative assessments and treatments. The response to DBS was evaluated retrospectively using the Global Dystonia Rating Scale (GDS).

Results: Out of $585 \mathrm{~dB}$ implantations during the study period, 37 were done for dystonia. The clinical response improved significantly with time in the isolated focal dystonia group, and at 12 months, 22 of 32 patients had over 50\% alleviation of the GDS score. There was only one subclinical intracerebral haemorrhage, and four infections leading to revision. Speech impairment and limb coordination problems were common stimulation- related adverse events and were mostly resolved or relieved with the adjustment of stimulation parameters.

Conclusions: DBS seems to be beneficial in dystonia. Although DBS is indicated for dystonia in Finland, the number of operations did not increase at the same rate as DBS operations in general. DBS appears to be a safe and effective treatment for focal as well as generalized dystonia.
\end{abstract}

Keywords: Deep brain stimulation, Dystonia, Generalized dystonia, Focal dystonia

\section{Background}

Dystonia is a heterogeneous group of disorders, characterized by sustained or intermittent muscle contraction causing abnormal postures and/or repetitive movements with unknown aetiology [1]. It is the third most common movement disorder after essential tremor and Parkinson's disease (PD) considerably affecting the quality of life and ability to work [2].

Currently there are only symptomatic treatments for dystonia, the most effective being oral treatment with anticholinergic drugs for generalized dystonia and intramuscular botulinum neurotoxin (BoNT) treatment for focal dystonia, specifically for cervical dystonia, as the first line treatment [3]. However, several patients do not respond to BoNT treatment or they lose the effect over

\footnotetext{
* Correspondence: rebekka.ortiz@helsinki.fi

${ }^{1}$ Department of Neurology, Helsinki University Hospital, Haartmaninkatu 4, 00029 HUS Helsinki, Finland

${ }^{2}$ Department of Clinical Neurosciences (Neurology), University of Helsinki, Helsinki, Finland
}

time. Further, the response to oral pharmacotherapy, used particularly in generalized dystonia, is frequently inadequate and has several side effects [4].

High-frequency deep brain stimulation (DBS) targeting bilaterally globus pallidus interna (GPi) has been established as effective second line treatment in medically refractory dystonia with severely impaired quality of life [5-9]. DBS is considered a safe alternative to pallidotomy because of its reversibility, lower complication risk for bilateral procedures and adjustment possibilities [10]. DBS is recommended for generalized and segmental primary dystonia (level A recommendation) and in medical-refractory focal dystonia (level B) $[10,11]$. In acquired dystonia, DBS is considered less effective, with the exception of tardive dystonia (level C) [11].

The aim of this study was to evaluate the use and outcomes of dystonia DBS in Finland. We specially focused on indications, response and adverse events. Using patient databases and medical records, we retrospectively 
studied dystonia patients treated with DBS in Finland between the years 2007-2016.

\section{Methods}

We retrospectively analysed the hospital records of patients, who were diagnosed with dystonia (ICD-10 diagnoses G24.1-G24.9) and underwent DBS operation between 1.1.2007 and 31.12.2016 at four out of five DBS centres in Finland. The data of fifth centre with four patients was not available. Data of four patients were removed from further analysis. One patient had essential tremor, one had Tourette syndrome and two patients were excluded because DBS was removed 1 week after operation for unknown reasons.

The following data was obtained from the files: patient age on operation day, maximum follow up time, gender, the day of DBS operation, re-operations and removal of DBS, the type of the DBS generator, stimulation parameters at six and 12 months, the centre where operated, diagnosis and classification of dystonia, the duration of symptoms before operation, whether patient had neuropsychological or psychiatric evaluation, if the patient was able to work after operation, previous BoNT injections, and whether the BoNT injections continued after DBS. The device and stimulation -related perioperative and long-term adverse events during maximum follow-up time were analysed. Adverse events were categorized into adverse events needing no action or resolving with programming and serious adverse events requiring hospital admission. No exact target coordinates were available from patient records.

The motor response to DBS was retrospectively estimated from patient records at six and 12 months after primary DBS operation using the Global Dystonia Severity Rating Scale (GDS) [12]. The GDS score was evaluated from different body areas from 0 to 10 (0 being no dystonia in body area, 1 minimal dystonia, 5 moderate dystonia, 10 most severe dystonia). The 10 areas tested were: eyes and upper face; lower face; jaw and tongue; larynx; neck; shoulder and proximal arm; distal arm and hand including elbow; pelvis and upper leg; distal leg and foot; trunk.

Due to non-normal distribution of the data, MannWhitney $U$-test was used to compare continuous independent factors including generator parameter values and GDS score between groups and Wilcoxon signed ranks tests for related factors including GDS score in different time points. Spearman correlation coefficient was used for correlation analyses between generator parameters and generator life. Bonferroni correction was used to account for multiple comparisons. $p<0.05$ was considered statistically significant. Normality testing was done using the Shapiro-Wilk test. The statistical analysis was done using SPSS version 24.0 (SPSS Inc., Chicago, IL, USA).

\section{Results}

Thirty-seven patients received DBS because of dystonia during the years 2007-2016 in Finland with a gradual annual increase of operations (Additional file 3: Figure S1). Twenty patients were operated in Helsinki, eight in Tampere, six in Oulu and three in Kuopio university hospitals. There was a total of 77 operations including primary implantations, generator changes and electrode revisions and removals. During the years 2007-2016, altogether $585 \mathrm{~dB}$ operations were performed, and dystonia DBS accounted on average for $6,4 \%$ of all DBS operations. The clinical characteristics of patients are summarized in Table 1.

All focal dystonia patients had isolated cervical dystonia. Of five segmental dystonia patients, one had cranio-cervical dystonia, three cervico-brachial dystonia, and one had severe blepharospasm with PISA-syndrome associated with Parkinson's disease. One patient had acquired hemidystonia and chorea after stroke. Of generalized dystonia patients, one had DYT-1 gene mutation and the two had positive family history without known gene mutation. One had neurodegeneration with brain iron accumulation (NBIA), one had generalized dystonic tremor and one had acquired tardive dystonia.

Before DBS, eleven patients were considered fit to work. Nineteen patients were either on a long sick leave or retired because of sickness and eight patients were retired because of age. Only three patients who were on a long sick leave with cervical dystonia returned to work after DBS.

In most cases, neither neuropsychological nor psychiatric evaluation was done (25 patients). Preoperative neuropsychological evaluation was performed in nine patients. Nine patients received psychiatric evaluation and five patients received both evaluations. Eleven patients had previously been diagnosed with depression, and five of them had preoperative psychiatric evaluation. Postoperatively, one patient with known depression reported worsening of symptoms. Two patients, with no diagnosis of depression, reported postoperative significant depression. Two patients had preoperative memory problems, one with NBIA, but were evaluated in neuropsychological tests as eligible for DBS. In one patient cognitive problems worsened after DBS, probably due to the progression of NBIA. Both patients with previous cognitive problems had only minor benefit from DBS.

The clinical response as evaluated with GDS score improved significantly between preoperative state and at 6 months after operation in the isolated dystonia group $(p<0.005$, Wilcoxon signed ranks test). The improvement of the GDS score continued at 12 months even though the difference between six and 12 months was not significant. At 12 months, the mean reduction in GDS score was $55 \%$ and 22 of 32 patients had over $50 \%$ alleviation. Out of 10 patients with less benefit, 6 had 
Table 1 The clinical characteristics of DBS patients

\begin{tabular}{|c|c|c|c|c|c|}
\hline & $\begin{array}{l}\text { Focal } \\
(n=21)\end{array}$ & $\begin{array}{l}\text { Generalized } \\
(n=10)\end{array}$ & $\begin{array}{l}\text { Segmental } \\
(n=5)\end{array}$ & $\begin{array}{l}\text { Hemidystonia } \\
(n=1)\end{array}$ & $\begin{array}{l}\text { All } \\
(n=37)\end{array}$ \\
\hline Female & $13(62 \%)$ & $6(60 \%)$ & $3(60 \%)$ & $1(100 \%)$ & $23(62 \%)$ \\
\hline Male & $8(38 \%)$ & $4(40 \%)$ & $2(40 \%)$ & & $14(38 \%)$ \\
\hline Mean age at operation $\pm S D$, years & $51,9 \pm 6,6$ & $45,7 \pm 19,3$ & $58,9 \pm 8,5$ & 25,7 & $50,3 \pm 12,9$ \\
\hline Mean follow-up time $\pm S D$, months & $19 \pm 13$ & $19 \pm 16$ & $25 \pm 18$ & 96 & $22 \pm 19$ \\
\hline \multicolumn{6}{|l|}{ Etiology } \\
\hline Idiopathic & $21(100 \%)$ & $8(80 \%)$ & $5(100 \%)$ & & $34(92 \%)$ \\
\hline Inherited & & $1(10 \%)$ & & & $1(3 \%)$ \\
\hline Acquired & & $1(10 \%)$ & & $1(100 \%)$ & $2(5 \%)$ \\
\hline \multicolumn{6}{|l|}{ Nervous system pathology } \\
\hline No evidence & $21(100 \%)$ & $5(50 \%)$ & $4(80 \%)$ & & $30(81 \%)$ \\
\hline Structural lesion & & $3(27 \%)$ & & $1(100 \%)$ & $4(11 \%)$ \\
\hline Degeneration & & $2(18 \%)$ & $1(20 \%)$ & & $3(8 \%)$ \\
\hline \multicolumn{6}{|l|}{ Clinical characteristics } \\
\hline \multicolumn{6}{|l|}{ Associated features } \\
\hline Isolated dystonia & $21(100 \%)$ & $5(50 \%)$ & $4(80 \%)$ & & $30(81 \%)$ \\
\hline combined dystonia & & & & $1(100 \%)$ & $1(3 \%)$ \\
\hline Other neurological manifestation & & $5(50 \%)$ & $1(20 \%)$ & & $6(16 \%)$ \\
\hline \multicolumn{6}{|l|}{ Disease course } \\
\hline Stabile & $20(95 \%)$ & $3(30 \%)$ & $2(40 \%)$ & $1(100 \%)$ & $26(70 \%)$ \\
\hline Progressive & $1(5 \%)$ & 7 (70\%) & $3(60 \%)$ & & $11(30 \%)$ \\
\hline \multicolumn{6}{|l|}{ Age at onset } \\
\hline $3-12$ years & & $5(50 \%)$ & & & $5(14 \%)$ \\
\hline $13-20$ years & $2(9 \%)$ & $1(10 \%)$ & & & $3(8 \%)$ \\
\hline $21-40$ years & $10(48 \%)$ & $1(10 \%)$ & & $1(100 \%)$ & $12(32 \%)$ \\
\hline over 40 years & $9(43 \%)$ & $3(30 \%)$ & $5(100 \%)$ & & $17(46 \%)$ \\
\hline \multicolumn{6}{|l|}{ Symptoms before DBS } \\
\hline under 10 years & $9(43 \%)$ & $5(50 \%)$ & $4(80 \%)$ & $1(100 \%)$ & 19 (51\%) \\
\hline over 10 years & $12(57 \%)$ & $5(50 \%)$ & $1(20 \%)$ & & $18(49 \%)$ \\
\hline \multicolumn{6}{|l|}{ Working ability before DBS } \\
\hline Fit to work, full-time & $7(33 \%)$ & $3(30 \%)$ & $1(20 \%)$ & & $11(30 \%)$ \\
\hline Unable to work & $11(52 \%)$ & $4(40 \%)$ & $2(40 \%)$ & $1(100 \%)$ & 19 (51\%) \\
\hline Retired because of age & $3(14 \%)$ & $3(30 \%)$ & $2(40 \%)$ & & $8(19 \%)$ \\
\hline
\end{tabular}

mediocre response with stimulation related side effects. Only 4 patients did not benefit at all, one of them had NBIA, one had other progressive generalized dystonia and two had marked side effects with increased stimulation. In the heterogeneous combined dystonia group, the results varied more and no significant improvement was seen (Fig. 1a). In the combined dystonia group, the patient with post-stroke hemidystonia had the best response with 75\% drop in GDS score. The preoperative mean GDS was $7,3 \pm 2,1$ in isolated focal dystonia patients and 12,5 $\pm 3,7$ in isolated general dystonia patients reflecting the different clinical phenotype of these groups. The clinical response improved significantly with isolated focal dystonia patients, the reduction in GDS score was $65 \%$ between preoperative score and 12 months. A similar non-significant trend was seen with isolated general dystonia patients $(60 \%$ reduction in GDS score) (Fig. 1b).

The clinical response as measured with GDS at 6 and 12 months with isolated dystonia patients did not differ between age groups under vs. over 50 years, duration of disease under vs. over 10 years, or patients with vs. without previously diagnosed depression (Additional file 1: Table S1). 

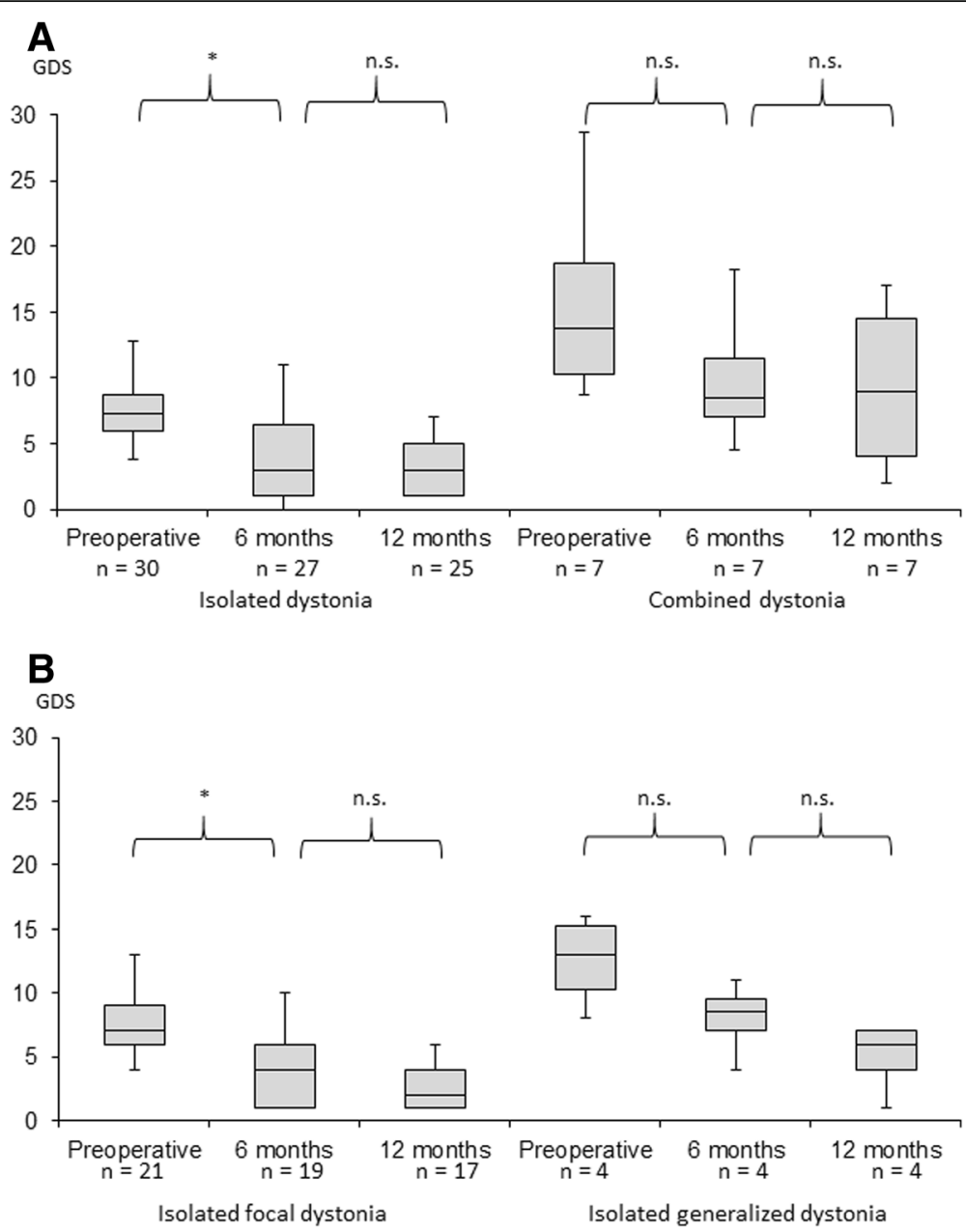

Fig. 1 Box-and-whisker-plot of clinical response estimated by GDS. a The GDS preoperatively and at six and twelve months, respectively, in isolated and combined dystonia. b The GDS preoperatively and at and twelve months, respectively, in isolated focal and generalized dystonia. The box represents inter-quartile range, middle line represents median and upper and lower whiskers extend to 95th and 5th percentile. ${ }^{*}=p<0.005$. n.s. $=$ not significant

All patients had had preoperative brain MRI to calculate electrode trajectory and target. Microelectrode recording (MER) was used in all but the largest centre (18/38 patients) to pinpoint the target. Postoperatively, the correct electrode positioning was confirmed by brain computer tomography in all patients and evaluated by the operating neurosurgeon in each center.

All patients had primarily non-rechargeable dualchannel Medtronic Activa PC implantable pulse generator (IPG), except one patient, who had Medtronic Kinetra IPG. One patient had primarily temporary pulse generator that was replaced after 2 months with permanent IPG (Activa PC). Quadripolar electrodes were located bilaterally in GPi, except in one patient with acquired hemidystonia, who had unilateral combined VIM and GPi electrodes. Contacts were selected according to mark points based on stereotactic positioning on MRI/ CT fusion scans and/or MER in the beginning and adjusted later according to clinical response. There was no significant difference at 12 months in clinical response (CGI-C) between patients that had been operated with and without MER (Additional file 1: Table S1).

Focal dystonia patients had significantly longer mean duration of generator life at first replacement than general dystonia patients $(p<0.05$, Mann-Whitney $\mathrm{U}$ test) (Table 2). The number of patients was too small to statistically compare differences for second and third generator replacements. Only one rechargeable IPG was changed during study period, since it depleted completely because of charging difficulties.

There was a significant inverse correlation between DBS voltage setting and generator life, but not with pulse width or frequency at 12 months $(\mathrm{r}=-0,566, p<0.05$, Spearman correlation) (Additional file 4: Figure S2). The mean stimulation parameters are summarized in Table 3. For all patients, constant-voltage stimulation was used. 
Table 2 Generator replacement operations

\begin{tabular}{|c|c|c|c|}
\hline & $\begin{array}{l}\text { First } \\
(n=22)\end{array}$ & $\begin{array}{l}\text { Second } \\
(n=5)\end{array}$ & $\begin{array}{l}\text { Third } \\
(n=2)\end{array}$ \\
\hline \multicolumn{4}{|c|}{ Generator life $\pm S D$, months } \\
\hline Focal dystonia & $23 \pm 5,7(n=13)$ & $14 \pm 0,2(n=2)$ & $6(n=1)$ \\
\hline $\begin{array}{l}\text { Generalized } \\
\text { dystonia }\end{array}$ & $15 \pm 6,3(n=5)$ & $19 \pm 8,0(n=3)$ & $26(n=1)$ \\
\hline All & $21 \pm 7,2(n=22)$ & $17 \pm 6,5(n=5)$ & $21 \pm 7,2(n=2)$ \\
\hline \multicolumn{4}{|l|}{ Type } \\
\hline $\begin{array}{l}\text { Medtronic } \\
\text { Activa PC }\end{array}$ & 10 & 3 & 1 \\
\hline $\begin{array}{l}\text { Medtronic } \\
\text { Activa RC }\end{array}$ & 12 & 2 & 1 \\
\hline
\end{tabular}

There was only one postoperative subclinical intracerebral haemorrhage detected in routine computer tomography control right after the operation. Four patients developed infection leading to the removal of the device. Eleven patients $(30 \%)$ had postoperative antibiotics, in most cases, the medication was given for mild superficial infections. One patient's DBS treatment was discontinued after 2 years because of device-related infection and patient's suboptimal commitment to DBS treatment.

Operation-, hardware- and stimulation-related adverse events are summarized in Table 4. The rate of serious adverse events (SAE) and adverse events (AE) did not differ between age groups, dystonia types or patients that had been operated with and without MER (Additional file 2: Table S2).

Altogether four revisions and seven removal operations were done in eight patients.

The most common stimulation related adverse events were dysarthria, impaired upper and lower limb coordination and impaired balance. DBS programming relieved often adverse events, even though the adverse events were not completely resolved in all cases. Adverse events requiring hospital admission occurred in two patients. One patient received a percutaneous gastric tube because

Table 3 Stimulation parameters

\begin{tabular}{llll}
\hline & $\begin{array}{l}\text { Focal } \\
(n=17)\end{array}$ & $\begin{array}{l}\text { Generalized } \\
(n=9)\end{array}$ & $\begin{array}{l}\text { All } \\
(n=31)\end{array}$ \\
\hline Amplitude \pm SD $(\mathrm{V})$ & $2,9 \pm 0,8$ & $3,5 \pm 0,7$ & $3,0 \pm 1,1$ \\
Pulse width \pm SD $(\mu \mathrm{s})$ & $280 \pm 117$ & $246 \pm 125$ & $270 \pm 115$ \\
$\begin{array}{l}\text { Frequency } \pm \text { SD }(\mathrm{Hz}) \\
\begin{array}{l}\text { Stimulation type } \\
\text { Monopolar }\end{array}\end{array}$ & $129 \pm 22$ & $123 \pm 42$ & $130 \pm 30$ \\
$\begin{array}{l}\text { Bipolar } \\
\text { Interleave }\end{array}$ & 3 & 7 & 21 \\
Mixed & 2 & 1 & 5 \\
\hline
\end{tabular}

Table 4 Adverse events in DBS in dystonic patients

\begin{tabular}{llll}
\hline & $\mathrm{AE}^{\mathrm{a}}$ & $\mathrm{SAE}^{\mathrm{b}}$ & Resolved $^{\mathrm{C}}$ \\
\hline Operation and device-related & $\mathrm{n}(\%)$ & $\mathrm{n}(\%)$ & $\mathrm{n}$ \\
Antibiotic use due to wound problem & $11(30 \%)$ & & 11 \\
Infection leading to revision & & $4(11 \%)$ & 4 \\
ICH, subclinical & $1(3 \%)$ & & 1 \\
Device-related revision & & & \\
Intracranial electrode revision & & $2(5 \%)$ & 2 \\
IPG malfunction & & $2(5 \%)$ & 2 \\
IPG dislocation & & $1(3 \%)$ & 1 \\
Contact malfunction & & & 1 \\
Stimulation-related & $14(37 \%)$ & $1(3 \%)$ & 7 \\
Dysarthria & $4(11 \%)$ & $1(3 \%)$ & 3 \\
Dysphagia & $9(24 \%)$ & & 6 \\
dImpaired upper limb coordination & $7(19 \%)$ & & 3 \\
eImpaired lower limb coordination & $6(16 \%)$ & & 2 \\
Impaired balance & $4(11 \%)$ & 4 \\
Neck pain & $3(8 \%)$ & 2 \\
Anxiety / Depression & $3(8 \%)$ & 1 \\
Fatique & &
\end{tabular}

Symptoms complained by single patients: migraine, double vision and vision blurring, dizziness, and neck pressure, weight loss, hallucinations, tinnitus, and restlessness. $n=37 .{ }^{\mathrm{a}}$ Adverse event. ${ }^{\mathrm{b}}$ Serious adverse event. ${ }^{\mathrm{C}}$ Event resolved

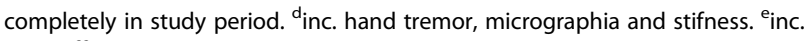
gait stiffness

of dysphagia, which, however, may also be explained by the progression of the underlying disease. One patient developed severe dysarthria because of DBS that did not respond to routine stimulation parameters and needed a speech communicator. However, the DBS treatment for dystonia was considered beneficial.

\section{Discussion}

DBS is established as an effective treatment for focal, segmental and generalized dystonia [5-7]. Our study assessed the Finnish dystonia DBS patients during 2007-2016. The number of dystonia as well as overall DBS operations has been steadily increasing during the study period. However, in proportion to the total number of DBS operations, dystonia related DBS operations have increased slowly in Finland. No data from other countries for comparison was available.

DBS alleviated dystonia symptoms in most patients, and specifically in patients with isolated cervical dystonia up to 12 months after operation. As compared to the meta-analysis by Moro et al., where the Burke-FahnMarsden Dystonia Rating Scale motor score improved $65 \%$ in isolated dystonia, our patients had slightly less improvement (55\%) [13]. However, the results are not directly comparable and in the meta-analysis better outcome was associated with greater dystonia severity. The 
majority of our patients had cervical dystonia, with not as high GDS scores and this might limit relative improvement. Only 4 patients did not benefit from DBS. One had progressive underlying disease (NBIA) and two had major side effects with increased stimulation. None of the patients in our study became completely symptom-free. Three patients who returned to work had focal dystonia.

The response to DBS remained at 12 months in focal dystonia patients. According to previous literature, the response has been reported to evolve in the first months after surgery, but the long-term effect seems to be sustained at least $5-10$ years $[9,14,15]$.

The patients in this study were older in comparison to the meta-analysis by Moro et al., mean age being 50 years compared with 35 years, respectively [13]. As cervical dystonia patients are generally older than generalized dystonia patients, the higher proportion of cervical dystonia probably raises the mean age in this study. The rate of adverse events did not differ between age groups in our study. It has been suggested that earlier DBS interventions result in better outcomes [16]. However, controversial results have been published [17-19]. Also, younger patients may benefit more from DBS [13, 19]. In our study, the duration of disease or age did not correlate with the clinical response in isolated dystonia.

Interestingly, the only patient with post-stroke hemidystonia had a good response. DBS after stroke remains a controversial issue, and there is insufficient data to give general recommendations about it [20].

In this study, about half of patients were referred for DBS once they were already retired or on long sick leave because of dystonia. It remains to be seen, whether earlier intervention in suitable dystonic patients may sustain working ability and reduce social life disabilities.

Present results showed no fatal adverse events or permanent damage. Only one subclinical ICH and four infections leading to revision occurred in our cohort. However, operation and device-related adverse events that led to hospitalization and/or reoperation occurred in eight patients. The type of adverse events was similar to previous studies, but the rate of adverse events was quite high. The occurrence did not differ between dystonia groups or different centres. Previously, the reported rate of adverse events has varied considerably, from 5 to $26 \%$, and in dystonia it is higher than in $\mathrm{PD}$, but comparable to rarer indications like epilepsy and Tourette syndrome [21]. In our patient material, the pulse width was higher than in previous studies, thus this might increase the number of side effects, specifically dysarthria. However, parameter adjustment resolved or relieved adverse events in most cases. In our cohort, technical problems including one electrode revision, were quite common (16\%), whereas previously reported lead fractures did not occur [21-23].
The stimulation-related dysarthria and limb coordination problems indicated most probably involvement of internal capsule stimulation. Adverse events were comparable to previous studies [24]. The observed proportion of stimulation related speech impairment was quite high. The result of a recent study suggests that posteriorly located active contacts in GPi may give rise to speech slowing in dystonic patients [25]. Unfortunately, the exact electrode location could not be defined in this study. It remains to be seen, whether the use of directional electrodes can decrease speech problems in patients with dystonia.

Psychiatric or cognitive adverse events were rare, only one patient with previously diagnosed depression complained of the worsening of depression and two other patients reported new onset of depression symptoms postoperatively.

Many centres consider MER as a gold standard for optimal targeting of the DBS lead during operation [26]. However, based on clinical outcome and adverse events, our results do not suggest superiority of MER over macrostimulation in dystonia.

The battery life was somewhat lower than in some previous studies, however, the IPG type was also different $[17,27,28]$. Pulse width was on average higher (270 $\mu$ s vs. $100-150 \mu$ s) while frequency and amplitude were similar in comparison with previous reports $[29,30]$. Logically voltage amplitude correlated inversely with battery life, but pulse width did not. Interestingly, the patients with focal dystonia had significantly longer battery life than generalized dystonia patients. The lower voltage values of focal dystonia patients might cause this, even though stimulation parameters did not significantly differ.

Rechargeable IPGs have shown to save costs and reduce infection risk because of fewer replacements compared with non-rechargeable IPGs [27]. Although 27 operations were done due to battery depletion, only 14 rechargeable IPGs were implanted. Most patients were satisfied with the rechargeable battery. However, the dependence on daily charging was the reason for some patients to remain with the non-rechargeable battery.

Being a retrospective uncontrolled observational study, this study comes with some limitations. The placebo effect could not be measured. The exact location of electrodes could not be retrieved from patient databases. Also, the assessment of GDS as well as complication data was based on patient records and not on systematical recording. Furthermore, the follow-up was available for most patients up to 12 months only. The amelioration of motor symptoms was evaluated, but the effects of reduced non-motor symptoms, such as pain, on GDS cannot be completely excluded. Moreover, the total amount of patients was small and especially the groups 
of generalized and segmental dystonia were heterogeneous, affecting the statistical analysis.

\section{Conclusion}

This study reinforces DBS as an effective treatment option for dystonia, although symptoms are usually not completely eliminated. The treatment is generally safe, and well tolerated after DBS adjustments, but the risk of adverse events needs to be taken into consideration. Present results also suggest that MER is not superior to macrostimulation in dystonia. The number of DBS operations in dystonia patients has grown slower than in other DBS indications in Finland. Thus, more emphasis should be put on increasing awareness of this treatment option in severe drug resistant dystonia.

\section{Additional files}

Additional file 1: Table S1. The clinical response as measured with GDS in different patient groups in isolated dystonia. The clinical response as measured with GDS at 6 and 12 months with isolated dystonia patients did not differ between age groups under vs. over 50 years, duration of disease under vs. over 10 years, patients with vs. without previously diagnosed depression or that had been operated with and without MER. (DOCX $13 \mathrm{~kb})$

Additional file 2: Table S2. The number of patients in different groups with AE and SAE. The rate of AE and SAE did not differ between age groups, dystonia types or patients that had been operated with and without MER. (DOCX $13 \mathrm{~kb}$ )

Additional file 3: Figure S1. The annual number of DBS operations in different dystonia types and total DBS operations in Finland. The number of DBS operations in dystonia are shown as stacked column graphs and total number of all DBS operations marked as line. The scale for number of dystonia DBS is on left and for total DBS operations on right. (TIF $811 \mathrm{~kb}$ )

Additional file 4: Figure S2. Scatter plot of generator life. Scatter plot of generator life versus amplitude (A), pulse width (B) and frequency (C), All cases were plotted individually. Black line represents regression line. There was a significant inverse correlation between DBS voltage setting and generator life, but not with pulse width or frequency at twelve months ( $r=-0,566, p<0.05$, Spearman correlation). (TIF $1504 \mathrm{~kb}$ )

\section{Abbreviations}

BoNT: Botulinum neurotoxin; DBS: Deep brain stimulation; GDS: Global Dystonia Severity Rating Scale; GPi: Globus pallidus interna;

MER: Microelectrode recording; NBIA: Neurodegeneration with brain iron accumulation; PD: Parkinson's disease

\section{Acknowledgements}

We thank neurologists Maija Koivu and Jaana Autere at University Hospitals of Helsinki and Kuopio, respectively and neurosurgeon Mikko Kauppinen at University Hospital of Oulu for the help in collecting patients' data.

\section{Authors' contributions}

$\mathrm{RO}, \mathrm{FS}$ and EP contributed to the conception, design and implementation of the research and to the interpretation and analysis of the results. $\mathrm{RO}$ collected the data. RO, FS and EP have been involved in drafting the manuscript or revising it critically for important intellectual content and given final approval of the version to be published. All authors agreed to be accountable for all aspects of the work in ensuring that questions related to the accuracy or integrity of any part of the work are appropriately investigated and resolved.

\section{Funding}

$\mathrm{RO}$ has received a grant from the Finnish Parkinson Foundation. The grant was used to fund the research and registry licenses and for 6 weeks salary for RO. Finnish Parkinson Foundation did not have any role in the design of the study; collection, analysis, and interpretation of data; and in writing the manuscript.

\section{Availability of data and materials}

The datasets analyzed during the current study are available from the corresponding author on reasonable request.

\section{Ethics approval and consent to participate}

The study had research permit from Finnish National Institute for Health and Welfare. The approval of ethics committee was not required because the research was based on hospital records and no patients were contacted.

\section{Consent for publication}

Not applicable.

\section{Competing interests}

$\mathrm{RO}$ has received a grant from the Finnish Parkinson Foundation. The foundation has no role regarding study design, data collection, analysis, decision to publish and preparation of the manuscript. This does not alter our adherence to BMC Neurology policies on sharing data and materials. Other authors have declared that no competing interests regarding this study exist.

$\mathrm{RO}$ has received travel support from Abbvie, Allergan and Zambon and participated in clinical trials by Portola Pharmaceuticals and Roche. FS is founder and CEO of Neurolnnovation Oy, has received consulting fees from Herantis Pharma, Orion Pharma, UCB, Renishaw, and LivaNova, lecture fees from Abbvie, UCB, Orion, and Zambon, and travel support from Abbvie, Herantis Pharma, Global Kinetics, UCB, Nordiclnfu Care, Zambon, and Medtronic, non-financial support from Abbott.

EP has received consulting fees from Nordiclnfu Care, Abbvie, Herantis Pharma, Zambon, lecture fees from Abbott, Abbvie, Lundbeck, Medtronic, and Orion, and travel support from Abbott, Abbvie, Boston Scientific, Herantis Pharma, Medtronic

Received: 21 December 2018 Accepted: 18 June 2019

Published online: 24 June 2019

\section{References}

1. Albanese A, Bhatia K, Bressman SB, Delong MR, Fahn S, Fung VS, et al. Phenomenology and classification of dystonia: a consensus update. Mov Disord. 2013;28:863-73.

2. Page D, Butler A, Jahanshahi M. Quality of life in focal, segmental, and generalized dystonia. Mov Disord. 2007;22:341-7.

3. Ramirez-Castaneda J, Jankovic J. Long-term efficacy and safety of botulinum toxin injections in dystonia. Toxins (Basel). 2013;5:249-66.

4. Termsarasab P, Thammongkolchai T, Frucht SJ. Medical treatment of dystonia. J Clin Mov Disord. 2016;3:6 eCollection 2016.

5. Volkmann J, Mueller J, Deuschl G, Kuhn AA, Krauss JK, Poewe W, et al. Pallidal neurostimulation in patients with medication-refractory cervical dystonia: a randomised, sham-controlled trial. Lancet Neurol. 2014;13:875-84.

6. Mueller J, Skogseid IM, Benecke R, Kupsch A, Trottenberg T, Poewe W, et al. Pallidal deep brain stimulation improves quality of life in segmental and generalized dystonia: results from a prospective, randomized sham-controlled trial. Mov Disord. 2008;23:131-4.

7. Halbig TD, Gruber D, Kopp UA, Schneider GH, Trottenberg T, Kupsch A. Pallidal stimulation in dystonia: effects on cognition, mood, and quality of life. J Neurol Neurosurg Psychiatry. 2005;76:1713-6.

8. Volkmann J, Wolters A, Kupsch A, Muller J, Kuhn AA, Schneider GH, et al Pallidal deep brain stimulation in patients with primary generalised or segmental dystonia: 5-year follow-up of a randomised trial. Lancet Neurol. 2012;11:1029-38.

9. Valldeoriola F, Regidor I, Minguez-Castellanos A, Lezcano E, Garcia-Ruiz P, Rojo A, et al. Efficacy and safety of pallidal stimulation in primary dystonia: results of the Spanish multicentric study. J Neurol Neurosurg Psychiatry. 2010;81:65-9.

10. Albanese A, Barnes MP, Bhatia KP, Fernandez-Alvarez E, Filippini G, Gasser T, et al. A systematic review on the diagnosis and treatment of primary 
(idiopathic) dystonia and dystonia plus syndromes: report of an EFNS/ MDS-ES task force. Eur J Neurol. 2006;13:433-44.

11. Albanese A, Asmus F, Bhatia KP, Elia AE, Elibol B, Filippini G, et al. EFNS guidelines on diagnosis and treatment of primary dystonias. Eur J Neurol. 2011;18:5-18.

12. Comella CL, Leurgans S, Wuu J, Stebbins GT, Chmura T, Dystonia Study Group. Rating scales for dystonia: a multicenter assessment. Mov Disord. 2003;18:303-12.

13. Moro E, LeReun C, Krauss JK, Albanese A, Lin JP, Walleser Autiero S, et al. Efficacy of pallidal stimulation in isolated dystonia: a systematic review and meta-analysis. Eur J Neurol. 2017;24:552-60.

14. Walsh RA, Sidiropoulos C, Lozano AM, Hodaie M, Poon YY, Fallis M, et al. Bilateral pallidal stimulation in cervical dystonia: blinded evidence of benefit beyond 5 years. Brain. 2013;136:761-9.

15. Loher TJ, Capelle HH, Kaelin-Lang A, Weber S, Weigel R, Burgunder JM, et al. Deep brain stimulation for dystonia: outcome at long-term follow-up. J Neurol. 2008;255:881-4.

16. Panov F, Gologorsky Y, Connors G, Tagliati M, Miravite J, Alterman RL. Deep brain stimulation in DYT1 dystonia: a 10-year experience. Neurosurgery. 2013:73:93 discussion 93.

17. Vidailhet M, Vercueil L, Houeto JL, Krystkowiak P, Lagrange C, Yelnik J, et al. Bilateral, pallidal, deep-brain stimulation in primary generalised dystonia: a prospective 3 year follow-up study. Lancet Neurol. 2007;6:223-9.

18. Bronte-Stewart H, Taira T, Valldeoriola F, Merello M, Marks WJ Jr, Albanese A, et al. Inclusion and exclusion criteria for DBS in dystonia. Mov Disord. 2011; 26(Suppl 1):5.

19. Isaias IU, Alterman RL, Tagliati M. Outcome predictors of pallidal stimulation in patients with primary dystonia: the role of disease duration. Brain. 2008: 131:1895-902

20. Witt J, Starr PA, Ostrem JL. Use of pallidal deep brain stimulation in postinfarct hemidystonia. Stereotact Funct Neurosurg. 2013;91:243-7.

21. Jitkritsadakul O, Bhidayasiri R, Kalia SK, Hodaie M, Lozano AM, Fasano A. Systematic review of hardware-related complications of deep brain stimulation: do new indications pose an increased risk? Brain Stimul. 2017:10:967-76.

22. Yianni J, Nandi D, Shad A, Bain P, Gregory R, Aziz T. Increased risk of lead fracture and migration in dystonia compared with other movement disorders following deep brain stimulation. J Clin Neurosci. 2004;11:243-5.

23. Oh MY, Abosch A, Kim SH, Lang AE, Lozano AM. Long-term hardwarerelated complications of deep brain stimulation. Neurosurgery. 2002;50:6

24. Tagliati M, Krack P, Volkmann J, Aziz T, Krauss JK, Kupsch A, et al. Long-term management of DBS in dystonia: response to stimulation, adverse events, battery changes, and special considerations. Mov Disord. 2011;26(Suppl 1):54.

25. Pauls KAM, Brockelmann PJ, Hammesfahr S, Becker J, Hellerbach A, VisserVandewalle $\mathrm{V}$, et al. Dysarthria in pallidal deep brain stimulation in dystonia depends on the posterior location of active electrode contacts: a pilot study. Parkinsonism Relat Disord. 2018;47:71-5.

26. Bour $\mathrm{L}$, Contarino MF, Foncke EM, de Bie RM, van den Munckhof $\mathrm{P}$, Speelman JD, et al. Long-term experience with intraoperative microrecording during DBS neurosurgery in STN and GPi. Acta Neurochir. 2010;152:2069-77.

27. Perez J, Gonzalez V, Cif L, Cyprien F, Chan-Seng E, Coubes P. Rechargeable or nonrechargeable deep brain stimulation in dystonia: a cost analysis. Neuromodulation. 2017;20:243-7.

28. Blahak C, Capelle HH, Baezner H, Kinfe TM, Hennerici MG, Krauss JK. Battery lifetime in pallidal deep brain stimulation for dystonia. Eur J Neurol. 2011;18: $872-5$.

29. Meoni S, Fraix V, Castrioto A, Benabid AL, Seigneuret E, Vercueil L, et al. Pallidal deep brain stimulation for dystonia: a long term study. J Neurol Neurosurg Psychiatry. 2017:88:960-7.

30. Skogseid IM, Ramm-Pettersen J, Volkmann J, Kerty E, Dietrichs E, Roste GK. Good long-term efficacy of pallidal stimulation in cervical dystonia: a prospective, observer-blinded study. Eur J Neurol. 2012;19:610-5.

\section{Publisher's Note}

Springer Nature remains neutral with regard to jurisdictional claims in published maps and institutional affiliations.

\section{Ready to submit your research? Choose BMC and benefit from:}

- fast, convenient online submission

- thorough peer review by experienced researchers in your field

- rapid publication on acceptance

- support for research data, including large and complex data types

- gold Open Access which fosters wider collaboration and increased citations

- maximum visibility for your research: over $100 \mathrm{M}$ website views per year

At $\mathrm{BMC}$, research is always in progress.

Learn more biomedcentral.com/submissions 